\title{
Anatomia e histoquímica da lâmina foliar de espécies conhecidas por quebra- pedra (Euphorbia prostrata Aiton, Euphorbia hyssopifolia L., Phyllanthus amarus Schumach. \& Thonn e Phyllanthus tenellus Roxb.)
}

CONCEIÇÃO, L.O. ${ }^{1 *}$; AOYAMA, E.M. ${ }^{1}$

Universidade Federal do Espirito Santo, Centro Universitário Norte do Espirito Santo, Departamento de Ciências Agrárias e Biológicas, Rodovia BR 101 Norte km 60, Litorâneo, São Mateus, ES, Brasil, CEP 29932-540 *Autor para correspondência: luena09@gmail.com

RESUMO: O presente trabalho teve por objetivo realizar estudo anatômico comparativo entre duas espécies de Euphorbia L. e duas de Phyllanthus L. conhecidas popularmente por quebrapedra, a fim de contribuir com a identificação das espécies, visando o controle de qualidade e testes histoquímicos para conhecimento e localização de substâncias, com intuito de fornecer subsídios para futuros estudos. As quatro espécies estudadas foram coletadas na cidade de São Mateus-ES. Foram realizadas análises anatômicas e histoquímicas da lâmina foliar. Em vista frontal, E. prostrata apresenta paredes celulares poligonais, enquanto em E. hyssopifolia as paredes são sinuosas. As espécies de Euphorbia se diferenciam pela presença de canais laticíferos e estrutura Kranz. Somente nas espécies de Phyllanthus foram observados cristais de oxalato de cálcio. $P$. tenellus difere de $P$. amarus pela presença de cristais romboédricos e $P$. amarus por exibir cristais prismáticos no mesofilo. $O$ estudo anatômico foliar foi de grande relevância para a diferenciação das espécies conhecidas por quebra-pedra, revelando ser um parâmetro eficaz e que pode auxiliar no controle de qualidade de plantas medicinais, bem como os testes histoquímicos podem fornecer informações para futuros estudos com quebra-pedra.

Palavras-chave: Euphorbiaceae, Phyllanthaceae, Planta medicinal.

\begin{abstract}
Leaf anatomy and histochemistry of species known as stonebreaker (Euphorbia prostrata Aiton, Euphorbia hyssopifolia L., Phyllanthus amarus Schumach. \& Thonn, and Phyllanthus tenellus Roxb.). This study aimed to compare the anatomical and histochemical perspective between two species of Euphorbia L. and two of Phyllanthus L., to contribute to their identification, aiming the quality control of medicinal plans. The four studied species were collected in the city of São Mateus, ES, Brazil. We performed anatomical and histochemical analyses of leaves, and all parameters were effective for species differentiation. In the anatomical analyses, we observed crystals only in the Phyllanthus species. Euphorbia species differed by the presence of laticifer channels and Kranz structure. In frontal and crosssectional view, P. tenellus differs from P. amarus by the presence of rhombohedral crystals. In front view, E. prostate presents polygonal cell walls, while in E. hyssopifolia the walls are winding. In the histochemical tests conducted on the leaf blade, P. amarus stands out by presenting negative reaction to ferric chloride. The anatomical and histochemical studies of leaves are really important to the knowledge and differentiation of species known as stonebreaker. However, phytochemical studies are needed for more detailed knowledge of substances from the secondary metabolism of the plant.
\end{abstract}

Keywords: Euphorbiaceae, Phyllanthaceae, Medicinal Plant.

\section{INTRODUÇÃO}

O emprego de plantas medicinais na recuperação da saúde tem evoluído ao longo dos tempos desde as formas mais simples de tratamento local, provavelmente utilizada pelo homem das cavernas, até as formas tecnologicamente sofisticadas da fabricação industrial utilizada pelo homem moderno (Lorenzi \& Matos, 2008).

A Organização Mundial de Saúde denomina

Recebido para publicação em 20/11/2015 
planta medicinal a todo vegetal que contenha, em um ou mais de seus órgãos, substâncias que possam ser utilizadas para fins terapêuticos ou que possam ser empregadas como precursores de semi-sínteses químico-farmacêuticas (OMS, 1999).

No aspecto social, as plantas medicinais têm papel fundamental, principalmente para as populações menos favorecidas (Lameira \& Pinto, 2008). Segundo Aita et al. (2009) cada vez mais a população brasileira busca alternativas para o tratamento de doenças. A maioria das pessoas não busca atendimento médico consumindo produtos que podem colocar em risco sua saúde (Aita et al., 2009).

Muitos são os casos de intoxicação com plantas, pois as semelhanças morfológicas levam as pessoas ao consumo de uma espécie acreditando ser outra (Verdam \& Da Silva, 2010). A identificação por anatomia, assim como a morfologia, apresenta papel relevante por ser uma análise rápida e de baixo custo, ser comparada a outros métodos que permitam fazer julgamento sobre a droga em questão, verificando sua identidade ou reconhecendo a presença de possíveis fraudes ou contaminações (Oliveira et al., 2005). Testes histoquímicos também são comumente utilizados na identificação de drogas. Por meio dos testes pode-se evidenciar, tanto a natureza das paredes celulares, como as inclusões celulares. (Oliveira \& Akissue, 1989, 2009).

As Phyllanthaceae foram tradicionalmente reconhecidas entre as Euphorbiaceae, mas trabalhos filogenéticos revelaram a necessidade de seu reconhecimento como independente (Souza \& Lorenzi, 2005; APG II, 2003). Além disso, Phyllanthaceae pode ser diferenciada de Euphorbiaceae pela ausência de látex e nectários extraflorais nas folhas, pelos lóculos do ovário biovulados e pelas sementes sem carúncula, características raras ou ausentes em conjunto nas Euphorbiaceae (Souza \& Lorenzi, 2005).

Euphorbiaceae Juss. e Phyllanthaceae Martinov são amplamentes distribuídas, com maior diversidade em regiões tropicais (Judd et al., 2009), apresentando gêneros com representantes comumente utilizados na medicina popular. Em Euphorbiaceae, dentre os gêneros que possuem espécies medicinais, se encontram na literatura Croton L., Euphorbia L. (Mwine \& Van Damme, 2011) e Jatropha L. (Hirota et al., 2010), e, em Phyllanthaceae, o gênero Phyllanthus L. (Souza \& Lorenzi, 2005).

Euphorbia é o gênero com maior número de espécies (2.400) na família Euphorbiaceae (Judd et al., 2009). No Brasil, compreende 64 espécies, sendo 31 endêmicas, ocorrendo em todos os estados (Steinmann et al., 2015). Phyllanthus também apresenta o maior número de espécies (1.270) dentre as Phyllanthaceae (Judd et al., 2009); no Brasil, compreende 88 espécies, sendo 54 endêmicas, ocorrendo em todos os estados (Secco et al. 2015).

As espécies estudadas são popularmente conhecidas por quebra-pedra, nome vulgar que designa tanto espécies do gênero Phyllanthus quanto espécies do gênero Euphorbia, como pode ser observado nos trabalhos realizados por Aita et al. (2009) e Silva et al. (2013). Diferentes espécies conhecidas por quebra-pedra são utilizadas pela população no tratamento de problemas renais, muitas vezes comercializadas fragmentadas e dificultando a correta identificação das espécies (Aita et al. 2009).

Pelo fato de plantas medicinais serem usadas erroneamente por muitos devido à má identificação e, em alguns casos por apresentarem semelhanças morfológicas que dificultam a identificação das mesmas, se faz necessário estudos do ponto de vista anatômico para facilitar o reconhecimento de espécies, bem como a realização de testes histoquímicos para localização de substâncias nas folhas, parte da planta comumente utilizada pela população. Portanto, nosso trabalho teve por objetivo realizar estudo anatômico comparativo entre duas espécies de Euphorbia L. e duas de Phyllanthus L. conhecidas popularmente por quebra-pedra, a fim de contribuir com a identificação das espécies, e o controle de qualidade através de testes histoquímicos para conhecimento e localização substancias como subsídio para fornecer subsídios para futuros estudos.

\section{MATERIAL E MÉTODOS}

\section{Material vegetal e locais de coleta}

Indivíduos de espécies conhecidas por quebra-pedra foram coletados no Campus da Universidade Federal do Espírito Santo (S $18^{\circ}$ 40.466' W 03951.774'; S 1840.506' W 03951.676') e no bairro Sernamby (S 1843.323' W 03951.163'; S $\left.18^{\circ} 43.245^{\prime} \mathrm{W}^{\circ} 39^{\circ} 51.216^{\prime}\right)$, São Mateus-ES, no período de janeiro de 2014 a março de 2015.

As espécies analisadas foram Euphorbia prostrata Aiton. (Figura 1A), e Euphorbia hyssopifolia L. (Figura 1B), pertencentes a família Euphorbiaceae. Phyllanthus amarus Schumach. \& Thonn (Figura 1C) e Phyllanthus tenellus Roxb. (Figura 1D) pertencentes a família Phyllanthaceae. De cada espécie foram coletados de 20 a 30 indivíduos adultos para análises anatômicas e testes histoquímicos. Parte do material botânico coletado foi depositado no herbário VIES da Universidade Federal do Espírito 

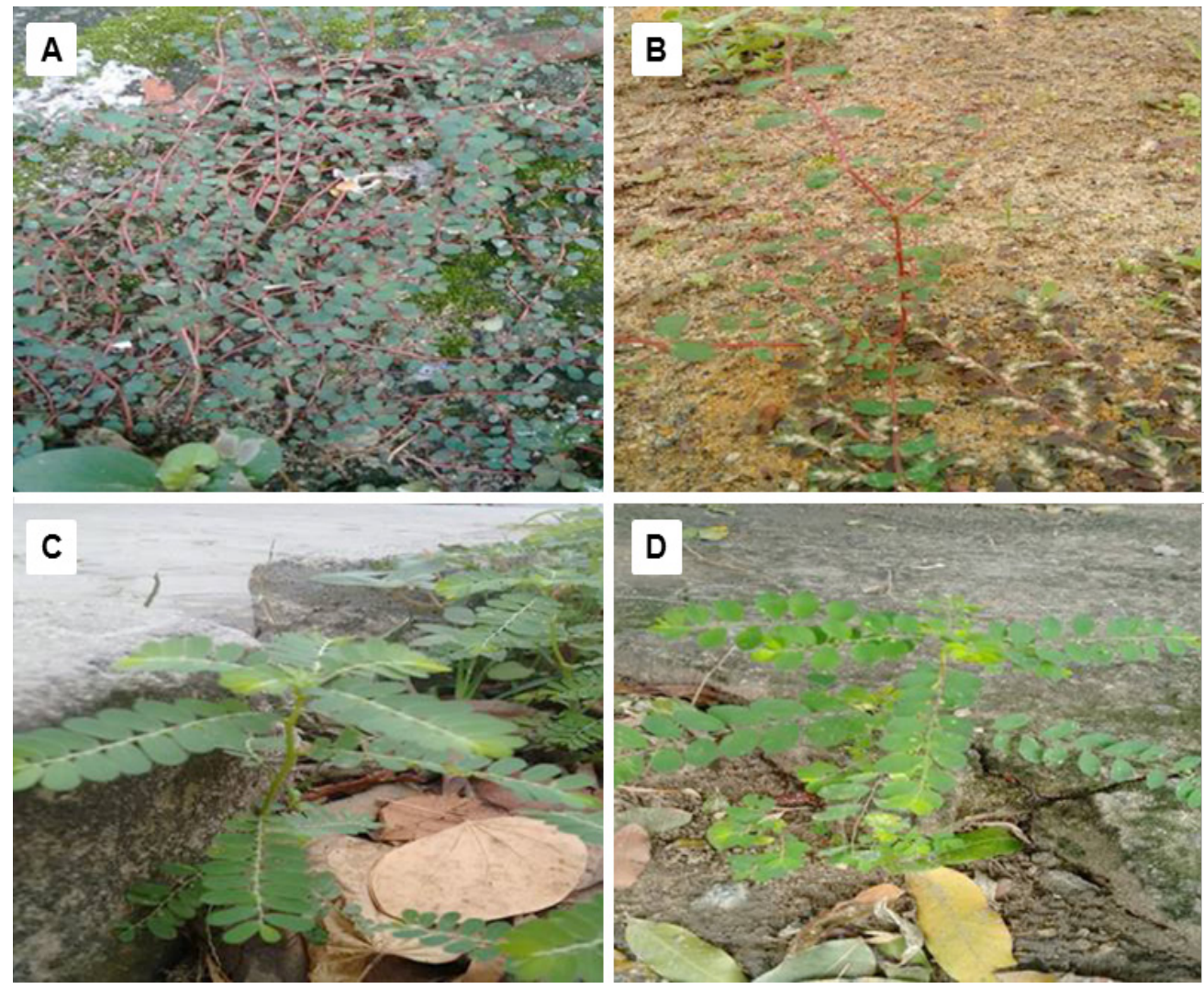

FIGURA 1. Aspectos gerais de indivíduos das espécies de quebra-pedra. A) Euphorbia prostrata Aiton.; B) Euphorbia hyssopifolia L.; C) Phyllanthus amarus Schumach. \& Thonn; D. Phyllanthus tenellus Roxb.

Santo sob os números 24640, 28330 (E. prostrata), 24638, 29060 (E. hyssopifolia), 23547, 29095 ( $P$. amarus), 24526, 24754 (P. tenellus). A identificação botânica foi realizada com base nas obras de Lorenzi (2000); Torres et al. (2003); Silva \& Sales (2004), e Silva (2014).

\section{Anatomia}

Para análise anatômica, os indivíduos foram fixados em FAA (formaldeído: ácido acético: álcool etílico 50\%, 2:1: $18 \mathrm{v} / \mathrm{v}$ ), de acordo com Johansen (1940) por 48 horas e posteriormente conservados em álcool $70 \%$.

O estudo anatômico foi realizado em folhas do $7^{\circ}$ a $9^{\circ}$ nós. Para visualização e classificação dos estômatos nas faces adaxial e abaxial, 5 folhas inteiras de cada espécie foram diafanizadas por aproximadamente 1 hora em solução de hidróxido de sódio a $10 \%$ e posteriormente em solução de hipoclorito de sódio a $25 \%$ por tempo determinado de acordo com a necessidade do material. As folhas foram coradas com safranina $1 \%$ (Shobe \& Lersten, 1967).

As secções transversais foram obtidas da região mediana da lâmina foliar e da nervura central, realizados à mão livre com auxílio de lâminas de barbear e isopor. O material seccionado foi selecionado e clarificado em solução de hipoclorito de sódio a $10 \%$, corado com azul de alcian $1 \%$ (Luque et al., 1996) e safranina 1\% (Shobe \& Lersten, 1967), e posteriormente foram montadas lâminas semipermanentes.

As lâminas foram analisadas ao microscópio óptico e as imagens obtidas em fotomicroscópio com projeção de escalas micrométricas.

\section{Testes histoquímicos}

Para os testes histoquímicos, secções transversais da lâmina foliar fixadas, não clarificadas, foram tratadas com: solução de Lugol para amido (Johansen, 1940); Ácido acético e Ácido clorídrico para verificação de composição química em cristais (Chamberlain, 1932 modificado por Kraus \& Arduin, 1997); Sudan IV em etanol para lipídeos totais (Pearse, 1972); Sudan IV em acetona e etanol para látex (Miller, 1968); solução aquosa de cloreto férrico para marcação de compostos fenólicos não estruturais (Johansen, 1940); solução de floroglucina ácida para compostos fenólicos estruturais (lignina) (Johansen, 1940).

Os modos de preparo e procedimentos de utilização dos reagentes foram realizados com base nas obras de Kraus \& Arduin (1997) e Ventrella et al. (2013). 


\section{RESULTADOS}

\section{Epiderme}

As espécies de Euphorbia L. apresentaram células epidérmicas com parede periclinal ondulada na face abaxial (Figura 2C, F). Esta ondulação é menos expressiva na face adaxial (Figura 2A$B$; D-E), sendo que, em E. prostrata, as paredes apresentaram contorno poligonal (Figura 2A-B). Nas espécies de Phyllanthus L., as células epidérmicas apresentaram ondulação semelhante em ambas às faces (Figura 3A-D). Em $P$. tenellus ocorrem idioblastos com cristais de oxalato de cálcio do tipo romboédrico (Figura 3C), que podem ser visualizados tanto na face adaxial quanto na abaxial. Em $P$. amarus não foram observados cristais na epiderme.

As quatro espécies exibiram folhas anfiestomáticas (Figura 2A-F) (Figura 3A-D). As lâminas foliares de E. prostrata e E. hyssopifolia revelaram estômatos anisocíticos a anomocíticos, e em $P$. amarus e $P$. tenellus estômatos paracíticos a menos frequentemente anomocíticos. $P$. amarus também apresentou estômatos do tipo anisocítico.

Ainda em vista frontal, foi possível a visualização de canais laticíferos, a princípio laticíferos não-articulados ramificados, nas Euphorbia L. (Figura 2B, E).

Secções transversais revelaram uma epiderme uniestratificada nas quatro espécies (Figura 4A-F) (Figura 5A-F), revestida por uma cutícula lipídica delgada (Figura 6A). E. prostrata apresentou células epidérmicas visualmente maiores na face adaxial (Figura 4B-C), o contrário ocorre em E. hyssopifolia, no qual as células epidérmicas da face abaxial são maiores em relação
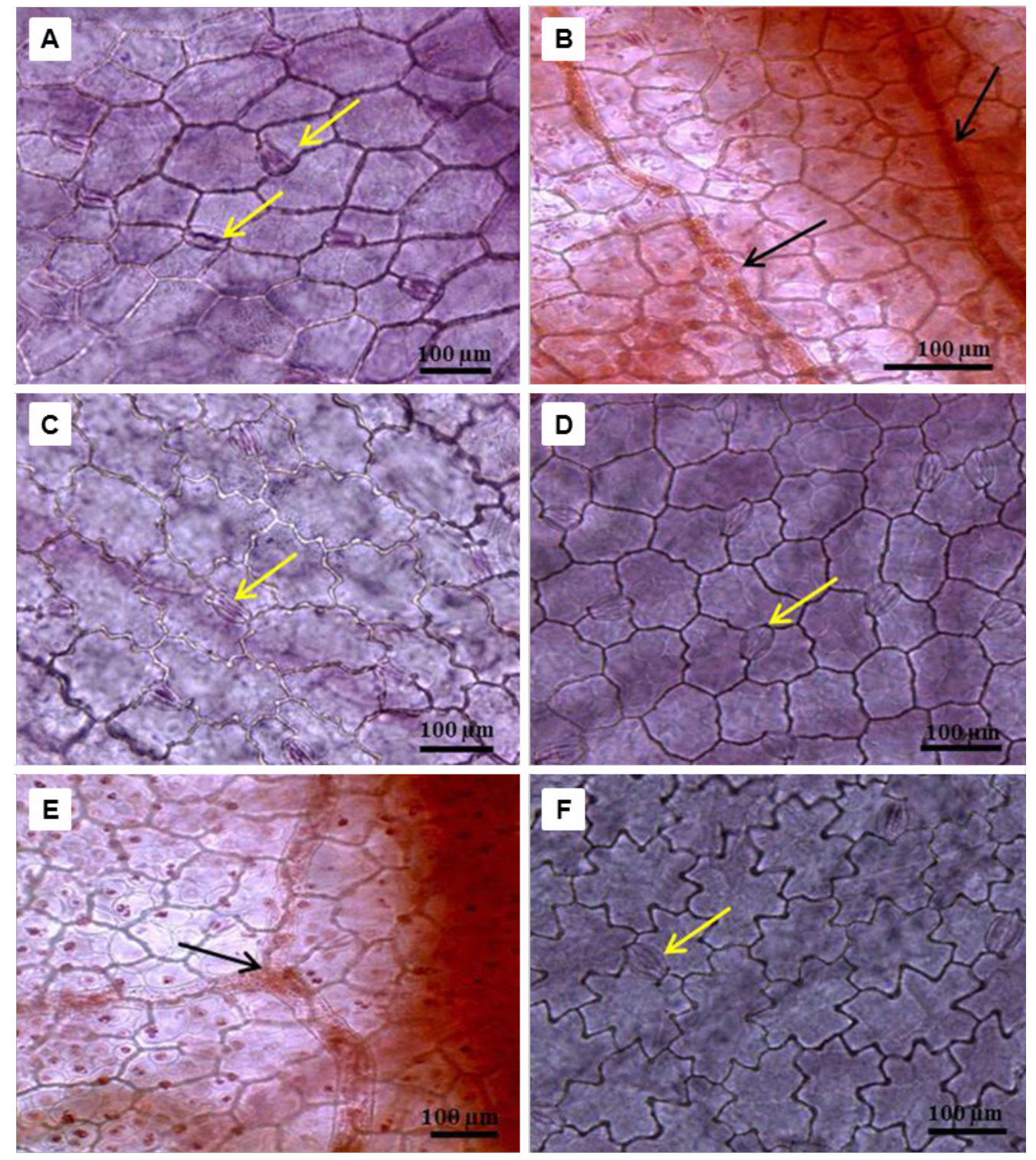

FIGURA 2. Vista frontal das espécies de quebra-pedra. A-C) Euphorbia prostrata; D-F) Euphorbia hyssopifolia. Face adaxial: A, B, D, E. Face abaxial: C, F. Seta amarela: estômatos; Seta preta: laticíferos. 

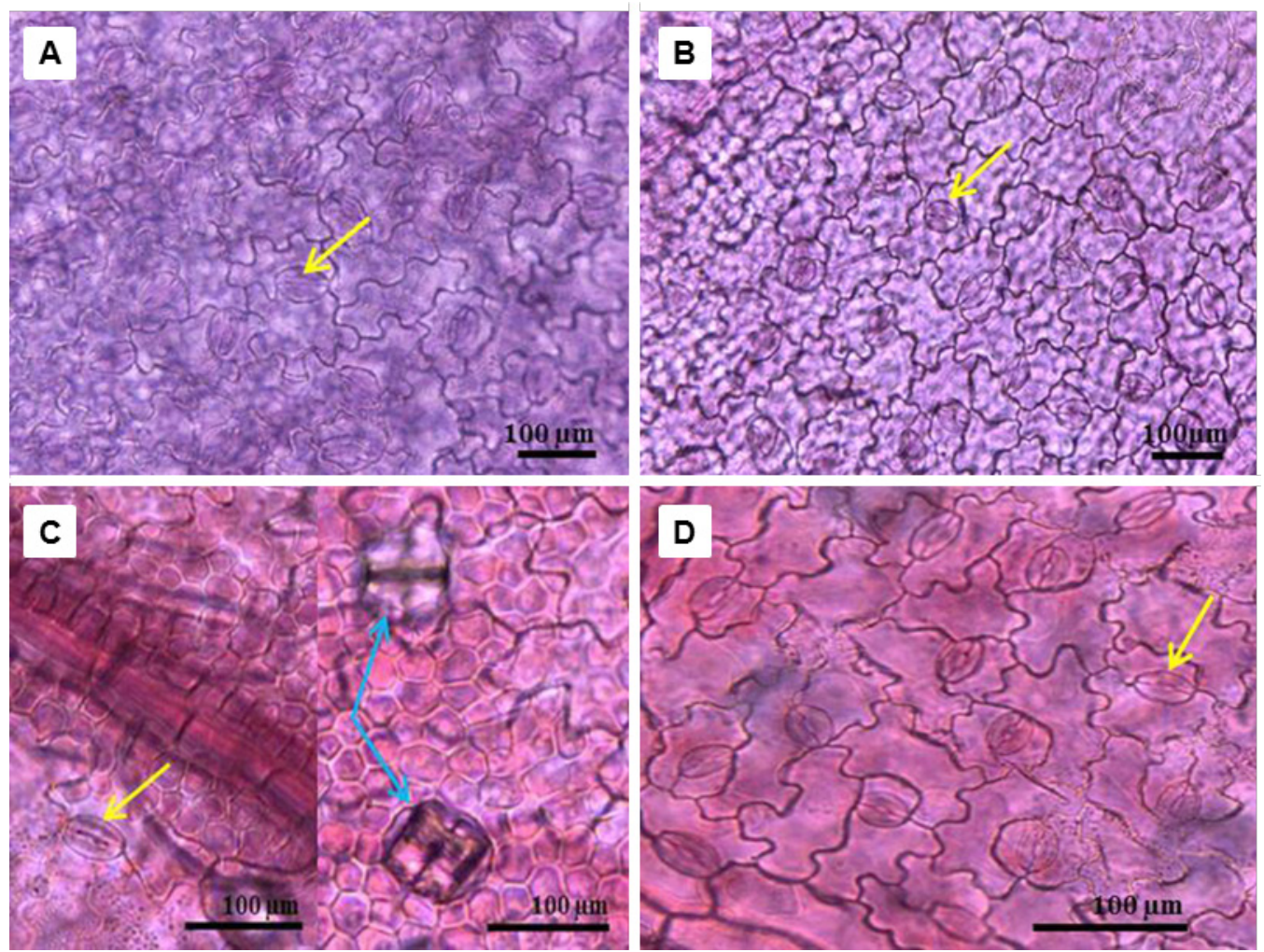

FIGURA 3. Vista frontal das espécies de quebra-pedra. A-B) Phyllanthus amarus; C-D) Phyllanthus tenellus. Face adaxial: A, C. Face abaxial: B, D. Seta amarela: estômatos; Seta azul: cristais romboédricos.

à adaxial (Figura 4E-F). Em P. amarus, as células da epiderme abaxial apresentaram contornos arredondados (Figura 5B-C), já em $P$. tenellus, tais células exibiram contornos irregulares e a face adaxial revelou uma projeção formada por células epidérmicas e colenquimáticas (Figura 5E-F).

\section{Mesofilo}

Secções transversais revelaram anatomia Kranz nas espécies de Euphorbia (Figura 4A-F). Apesar de apresentar anatomia Kranz em que geralmente o mesofilo é indiferenciado, é possível a visualização de camada uniestratificada de parênquima paliçádico na face adaxial ao longo da folha, e a maior concentração desse tipo de parênquima entre os feixes (Figura 4B-C; E-F).

As espécies de Phyllanthus L. apresentaram mesofilo dorsiventral, composto por camada uniestratificada de parênquima paliçádico (Figura $5 \mathrm{~A}-\mathrm{F}$ ). Nesta região do mesofilo, ocorrem grãos de amido em ambas as espécies (Figura 6B), compostos fenólicos em $P$. tenellus (Figura 6C), cristais de oxalato de cálcio do tipo prismático em $P$. amarus e romboédrico em $P$. tenellus. Cristais de oxalato de cálcio também ocorrem na nervura central (Figura 6D).

O mesofilo nas espécies de Phyllanthus mostrou-se diferente apenas na quantidade de camadas do parênquima lacunoso. Em $P$. amarus foi observado duas a três camadas de parênquima lacunoso (Figura 5C), e em $P$. tenellus duas camadas, na face abaxial (Figura 5F). Tais espécies apresentaram células epidérmicas algumas vezes papilosas principalmente na face abaxial.

\section{Região Intercostal}

Secções transversais da região intercostal apresentaram feixes vasculares ao longo do mesofilo nas espécies de Euphorbia L., envoltos por uma bainha constituída por células parenquimáticas, caracterizando assim a anatomia Kranz em E. prostrata e E. hyssopifolia (Figura 4C, F).

Nas espécies de Euphorbia foram detectados grãos de amido e compostos fenólicos na bainha que envolve os feixes vasculares, assim como na nervura central.

Ainda na região intercostal foi detectada a presença de látex, nas espécies de Euphorbia L., confirmando canais laticíferos no limbo (Figura 6E).

\section{Nervura central}

Em secção transversal da nervura central, o tecido de revestimento mostrou-se semelhante ao restante da folha.

Diferindo das espécies de Euphorbia L., em Phyllanthus ocorre um extrato de colênquima em ambas as faces, seguida por uma ou duas camadas de parênquima paliçádico na adaxial, que 
é interrompido ou não por células colenquimatosas. $P$. amarus nem sempre apresenta camada de colênquima após a epiderme da face adaxial.

$O$ feixe vascular é central do tipo colateral (Figura 4B, E) (Figura 5B, E) nas quatro espécies, com elementos de vaso lignificado voltado para a face adaxial (Figura 6F) e floema para a face abaxial. Na região da nervura central também foram observados canais laticíferos nas espécies de Euphorbia.

Os resultados dos testes histoquímicos podem ser visualizados de maneira resumida na tabela 1.

\section{DISCUSSÃO}

As espécies de Euphorbia apresentaram grandes semelhanças, sendo difícil a diferenciação

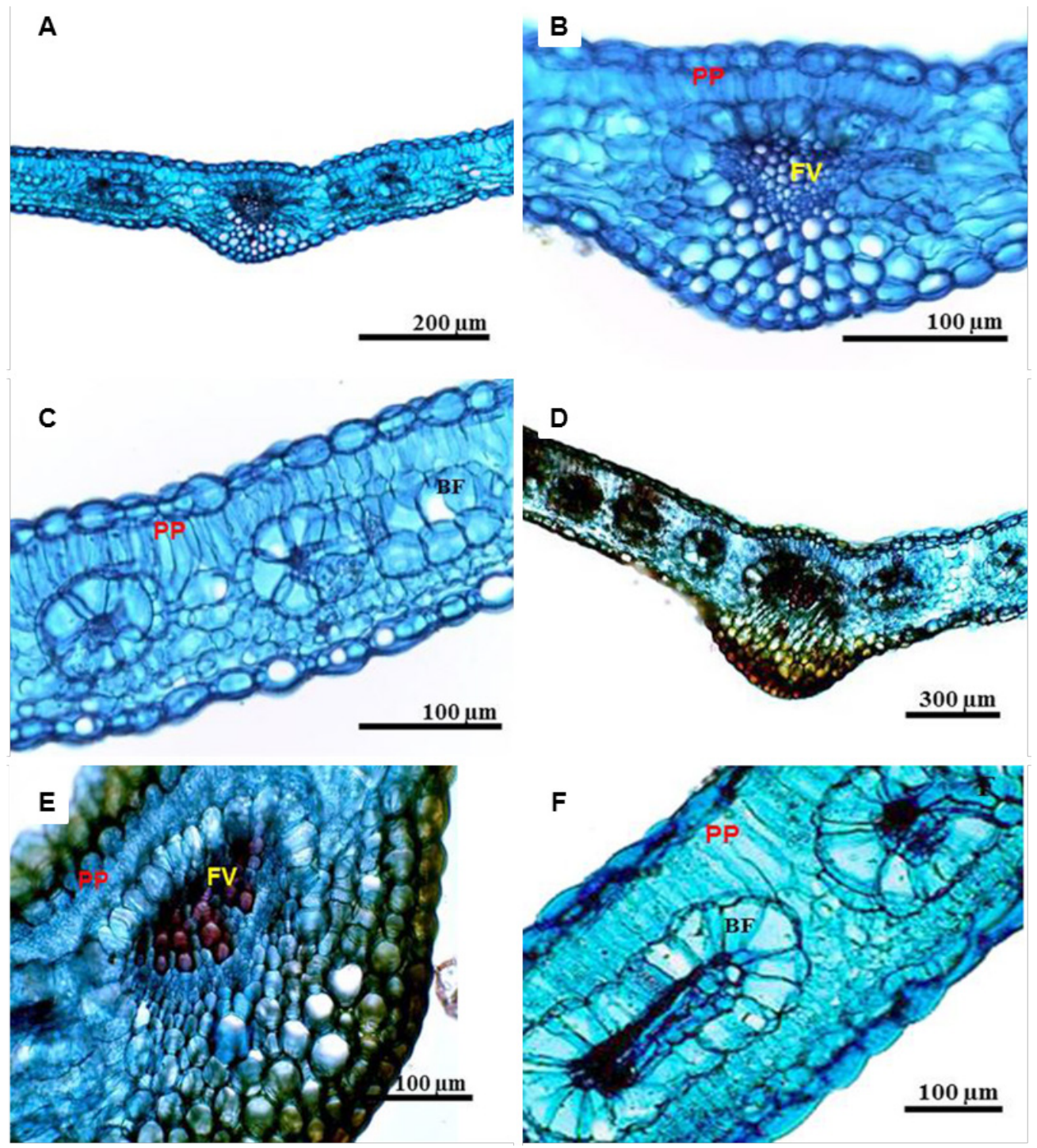

FIGURA 4. Secções transversais da lâmina foliar das espécies de quebra-pedra. A-C) Euphorbia prostrata; D-F) Euphorbia hyssopifolia. A, D: Vista geral do corte. B, E: Nervura Central. C, F: mesofilo. FV: Feixe Vascular. PP: Parênquima Paliçádico. BF: Bainha do Feixe. das mesmas em análise anatômica, porém, destacamos em E. prostrata, células epidérmicas da face adaxial com paredes de contorno poligonal, Outras espécies do gênero apresentam esta característica, como relatado por Thakur \& Patil (2014) para Euphorbia helioscopia L. em que apresenta paredes retas em ambas as faces, e por Devi et al. (2013) que descreveu paredes anticlinais retas para E. dracunculoides Lam., E. deccanensis var. nallamalayana (JLEllis) VSRaju, E. nivulia Buch.-Ham, E. perbracteata Gage e E. tirucalli L., evidenciando ser uma característica comum em espécies de Euphorbia.

As quatro espécies revelaram folhas anfiestomáticas, diferindo da análise apresentada na Farmacopéia Brasileira (2010), que classifica as folhas de $P$. tenellus como hipoestomáticas. A frequência dos estômatos varia amplamente em distinguindo-a das demais espécies deste estudo. 

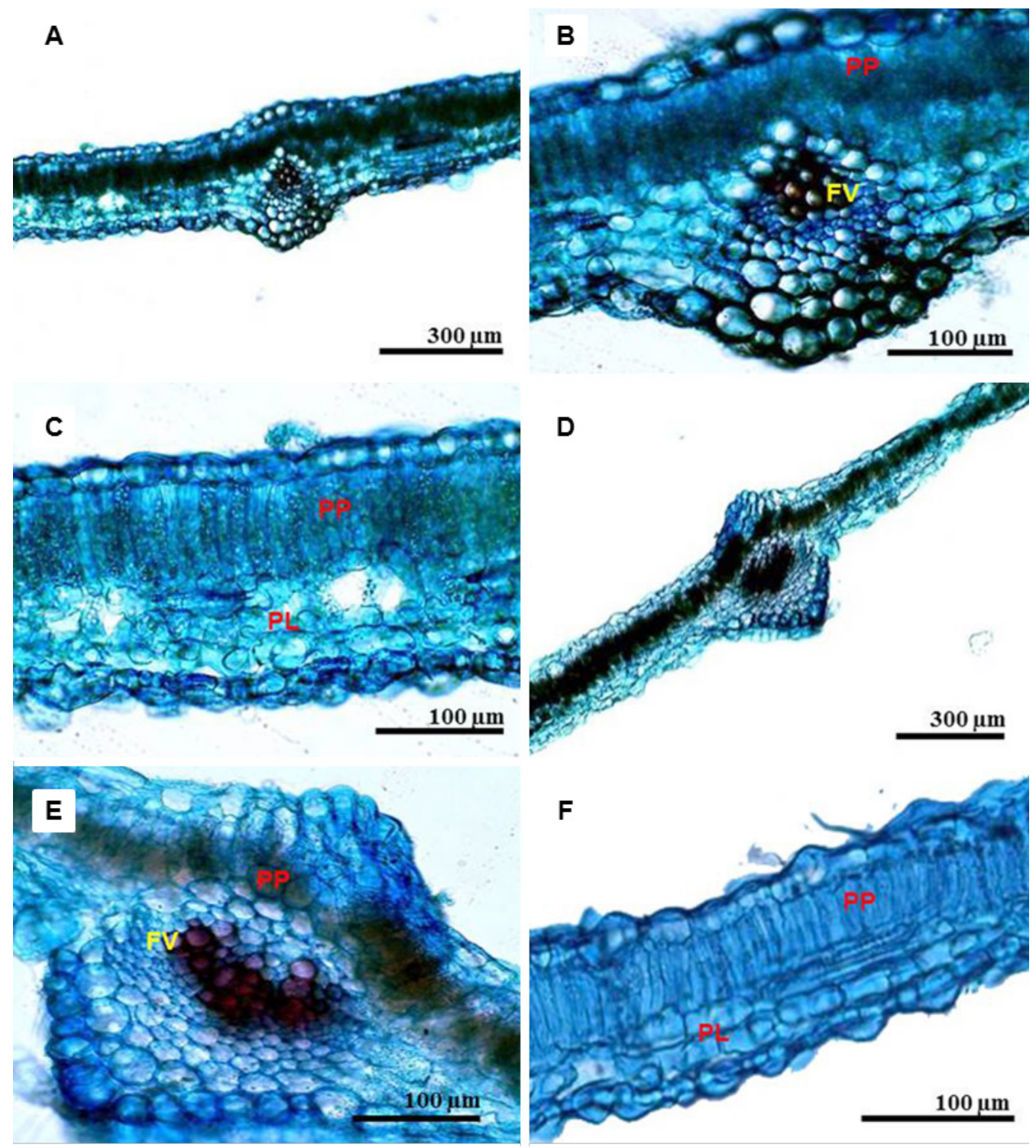

FIGURA 5. Secções transversais da lâmina foliar das espécies de quebra-pedra. A-C) Phyllanthus amarus; D-F) Phyllanthus tenellus. A, D: Vista geral do corte. B, E: Nervura Central. C, F: mesofilo. FV: Feixe Vascular. PP: Parênquima Paliçádico. PL: Parênquima Lacunoso.

diferentes partes da mesma folha e em diferentes folhas da mesma planta, e é influenciada pelas condições ambientais em que a planta se encontra (Esau, 1976). Deste modo, a posição dos estômatos na folha não pode ser considerada critério de diferenciação das espécies.

Além de estômatos do tipo anisocítico e anomocítico descrito neste estudo para as espécies de Euphorbia, Devi et al. (2013) relataram estômatos do tipo paracítico em E. hyssopifolia. Garcia et al. (2004) descreveram estômatos do tipo anisocítico em $P$. tenellus. Estômatos do referido tipo não foram observados para tal espécie neste estudo.

As quatro espécies revelaram epiderme uniestratificada revestida por uma cutícula lipídica delgada. Segundo Figueiredo et al. (2007) reservas lipídicas encontram-se, em geral, sob a forma de gotículas dispersas no citoplasma. Compostos lipídicos e seus derivados são ricamente encontrados em ceras e cutículas.

Destacamos anatomia Kranz em $E$. prostrata e E. hyssopifolia como característica principal para diferenciá-las das espécies de Phyllanthus, corroborando com Souza et al. (2014) que descreveu estrutura Kranz em cotilédones de E. prostrata. Tal característica também foi descrita para outras espécies de Euphorbia L., em estudos anatômicos realizados por Siqueira-Jaccoud (1956) e Elumalai et al. (2014).

Na região intercostal encontram-se grãos 

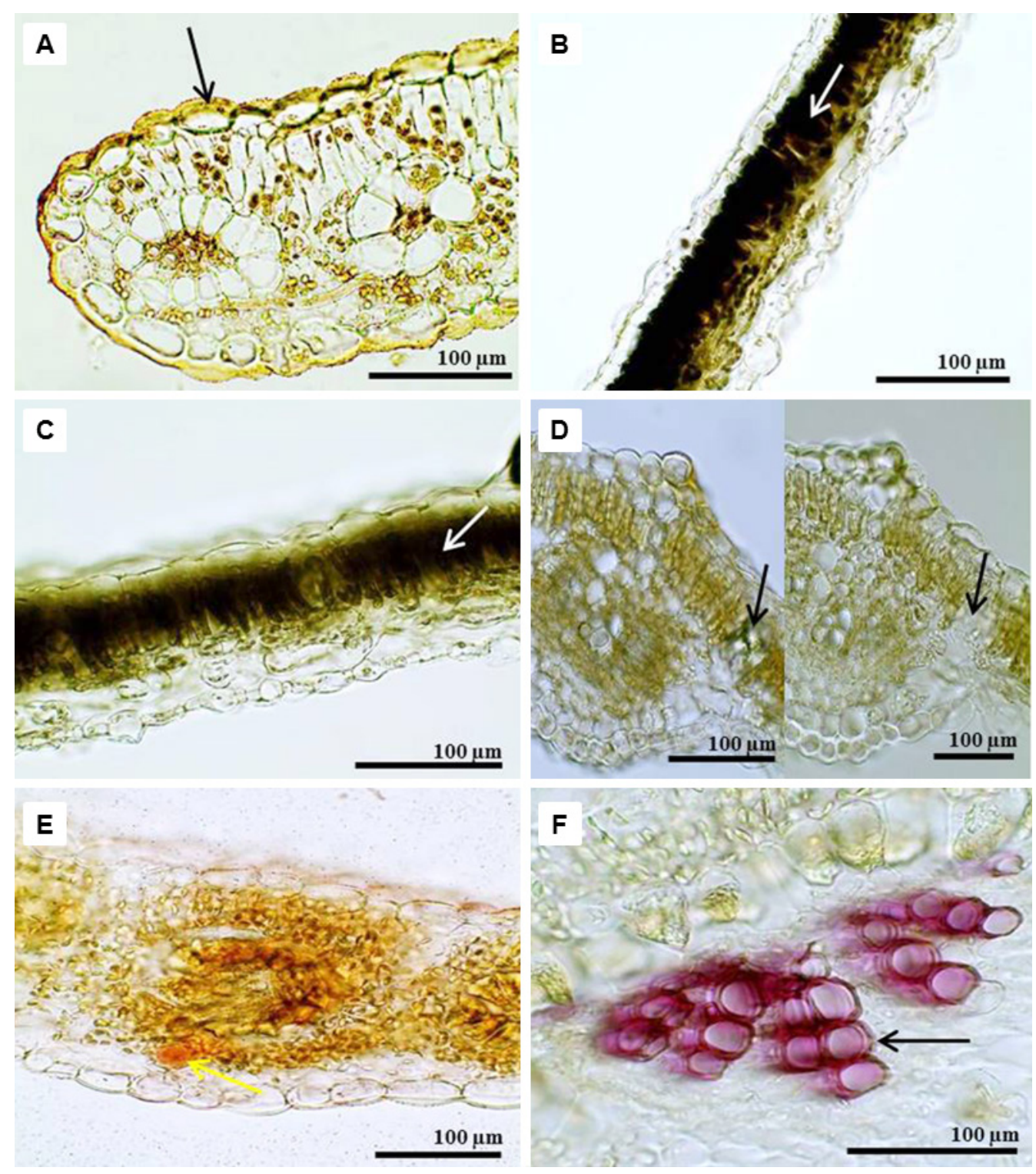

FIGURA 6. Secções transversais da lâmina foliar das quatro espécies de quebra-pedra submetidas a testes histoquímicos. A) Euphorbia prostrata (seta: presença de lipídio na cutícula). B) Phyllanthus tenellus (seta: amido no parênquima paliçádico). C) $P$. tenellus (seta: compostos fenólicos no parênquima paliçádico). D) P. tenellus (Seta: cristal romboédrico e dissolução do cristal em ácido clorídrico). E) E. hyssopifolia (seta: canal laticífero no mesofilo com presença de látex). F) P. amarus (seta: elementos de vaso lignificado na nervura central).

de amido nas bainhas que envolvem os feixes vasculares em Euphorbia, e no parênquima paliçádico em Phyllanthus. O amido é o produto resultante da polimerização de glicose formada nas plantas durante a fotossíntese. Apesar de ser uma substância muito frequente nos vegetais, são relativamente poucas as plantas utilizadas para a sua obtenção em grande escala (Oliveira \& Akissue, 1989).

Ainda no parênquima paliçádico de $P$. tenellus foi possível à detecção de compostos fenólicos, diferindo do ensaio histoquímico realizado por Santiago et al. (2000) em folhas maduras de $P$. tenellus, que demonstrou que as células do parênquima lacunoso são a principal fonte de compostos fenólicos e que estas substâncias estão acumuladas nas células aleatoriamente.

Segundo Croteau et al. (2010) esse grupo de compostos é importante para proteger as plantas contra os raios ultravioletas, insetos, fungos, vírus e bactérias.

A presença de cristais de oxalato de cálcio em $P$. amarus e $P$. tenellus é forte característica para diferenciá-las das espécies de Euphorbia. Além disso, ambas as espécies se diferem pelo tipo de cristal, visto que $P$. amarus possui do tipo prismático e $P$. tenellus do tipo romboédrico.

Diferente do observado neste estudo, 
TABELA 1. Testes histoquímicos do limbo, região da nervura central das quatro espécies de quebra-pedra.

\begin{tabular}{|c|c|c|c|c|c|c|c|}
\hline \multirow[b]{3}{*}{ Parte do vegetal/Espécie } & \multirow[b]{3}{*}{$\begin{array}{c}\text { Lipídios } \\
\text { totais }\end{array}$} & \multirow[b]{3}{*}{ Amido } & \multirow[b]{3}{*}{ Látex } & \multicolumn{4}{|c|}{ Substâncias } \\
\hline & & & & \multirow[b]{2}{*}{$\begin{array}{c}\text { Compostos } \\
\text { fenólicos }\end{array}$} & \multirow[b]{2}{*}{ Lignina } & \multicolumn{2}{|c|}{ Cristais } \\
\hline & & & & & & $\begin{array}{l}\text { Oxalato } \\
\text { de cálcio }\end{array}$ & $\begin{array}{c}\text { Carbonato } \\
\text { de cálcio }\end{array}$ \\
\hline \multicolumn{8}{|l|}{ Lâmina foliar } \\
\hline \multicolumn{8}{|l|}{ E. prostrata } \\
\hline \multicolumn{8}{|l|}{ Nervura Central } \\
\hline Cutícula & ++ & - & - & - & - & & \\
\hline Epiderme & - & - & - & - & - & & \\
\hline Parênquima & - & - & - & - & - & & \\
\hline Floema & - & - & - & - & - & & \\
\hline Xilema & - & - & - & - & ++ & & \\
\hline Bainha do feixe & - & ++ & - & + & - & & \\
\hline Laticífero & ++ & - & ++ & - & - & & \\
\hline \multicolumn{8}{|l|}{ E. hyssopifolia } \\
\hline \multicolumn{8}{|l|}{ Nervura Central } \\
\hline Cutícula & ++ & - & - & - & - & & \\
\hline Epiderme & - & - & - & - & - & & \\
\hline Parênquima & - & - & - & - & - & & \\
\hline Floema & - & - & - & - & - & & \\
\hline Xilema & - & - & - & - & ++ & & \\
\hline Bainha do feixe & - & ++ & - & + & - & & \\
\hline Laticífero & ++ & - & ++ & - & - & & \\
\hline \multicolumn{8}{|l|}{ P. amarus } \\
\hline \multicolumn{8}{|l|}{ Nervura Central } \\
\hline Cutícula & ++ & - & - & - & - & & \\
\hline Epiderme & - & - & - & - & - & & \\
\hline Parênquima & - & - & - & - & - & + & - \\
\hline Floema & - & - & - & - & - & & \\
\hline Xilema & - & - & - & - & ++ & & \\
\hline \multicolumn{8}{|l|}{ P. tenellus } \\
\hline \multicolumn{8}{|l|}{ Nervura Central } \\
\hline Cutícula & ++ & - & - & - & - & & \\
\hline Epiderme & - & - & - & - & - & & \\
\hline Parênquima & - & - & - & - & - & + & - \\
\hline Floema & - & - & - & - & - & & \\
\hline Xilema & - & - & - & - & ++ & & \\
\hline
\end{tabular}

Reação negativa (-) Moderadamente positiva (+) Fortemente positiva (++)

Garcia et al. (2004) não relataram presença de cristais em $P$. tenellus, porém, segundo Oliveira \& Akisue (2009), as inclusões de oxalato de cálcio são de grande importância na diagnose de drogas. A forma dos cristais, a localização e a frequência com que aparecem em certos órgãos vegetais constituem elementos de primeira ordem no reconhecimento da identidade de droga vegetal (Oliveira \& Akisue, 2009).

Os cristais de oxalato de cálcio são formados no metabolismo vegetal e armazenados no vacúolo das células (Scardelato et al., 2013). 
As inclusões de oxalato de cálcio são comuns e advêm da combinação do ácido oxálico resultante do metabolismo com os íons cálcio absorvidos pelos vegetais (Oliveira \& Akisue, 2009).

Segundo Scardelato et al. (2013), espécies como $P$. tenellus e $P$. niruri, utilizados no tratamento de cálculos renais e urolitíase e que apresentam grande quantidade de cristais de oxalato de cálcio nas partes utilizadas na medicina popular, podem acarretar problemas, sobretudo em indivíduos predispostos à formação de cálculos renais.

Por outro lado, Barros et al. (2006) analisaram o efeito do extrato aquoso de $P$. niruri em cálculos pré-formados induzidos pela introdução de oxalato de cálcio na bexiga de ratos. Os resultados obtidos no estudo sugerem, que a espécie $P$. niruri apresenta grande potencial terapêutico no tratamento de casos de urolitíase pela deposição de oxalato de cálcio. Isso mostra a importância da presença de cristais nas espécies de Phyllanthus L., levando em consideração que são plantas medicinais e que $P$. niruri possui grande semelhança com $P$. amarus e $P$. tenellus.

Foi possível a visualização de canais laticíferos em vista frontal da epiderme, na região intercostal e na nervura central nas Euphorbia, segundo descrição feita por Fahn (1979) sobre os tipos de laticíferos, aparentemente os encontrados são laticíferos não-articulados ramificados, assim como em Euphorbia milli (Souza, 2009), porém, para compreensão do real tipo do laticífero se faz necessário um estudo ontogenético (Fahn, 1979). Laticíferos são células altamente especializadas, definidas por sua anatomia característica e citoplasma distinto, conhecido como látex. Apesar de sua natureza incomum, o conteúdo dos laticíferos tem importância tradicional e contemporânea, como toxinas ou bioprodutos valiosos (Hagel et al, 2008).

Segundo Metcalfe \& Chalk (1985) laticíferos ocorrem extensamente na família Euphorbiaceae, sendo eles não-articulados em muitos membros da família, mas articulada em poucos outros, como em Hevea brasiliensis L. e Manihot glaziovii Müll. Arg.

$\mathrm{Na}$ nervura central, as quatro espécies exibiram feixe vascular central do tipo colateral com elementos de vaso lignificados. Segundo Saliba et al. (2001) a lignina é uma substância amorfa, de natureza aromática e muito complexa e faz parte da parede celular e da lamela média dos vegetais, além disso, tem um importante papel no transporte de água, nutrientes e metabólitos, sendo responsável pela resistência mecânica de vegetais, e protege os tecidos contra o ataque de microorganismos.

Os produtos secundários aumentam a probabilidade de sobrevivência de uma espécie, pois são responsáveis por diversas atividades biológicas com este fim como, por exemplo, podem atuar como antibióticos, antifúngicos e antivirais para proteger as plantas dos patógenos, e também apresentando atividades antigerminativas ou tóxicas para outras plantas, fitoalexinas (Fumagali et al., 2008).

\section{CONCLUSÃO}

O estudo anatômico foliar foi de grande relevância para a diferenciação das espécies conhecidas por quebra-pedra revelando ser um parâmetro eficaz e que pode auxiliar no controle de qualidade de plantas medicinais.

Os caracteres anatômicos descritos assemelham-se com as descrições feitas para espécies das famílias Euphorbiaceae e Phyllanthaceae por outros autores referidos anteriormente. A detecção e localização de substâncias na lâmina foliar através dos testes histoquímicos forneceram informações, que podem subsidiar futuros estudos.

\section{REFERÊNCIAS}

AITA, A.M. et al. Espécies medicinais comercializadas como "quebra-pedras" em Porto Alegre, Rio Grande do Sul, Brasil. Revista Brasileira de Farmacognosia, v.19, n.2, p.471-477, 2009.

APG II. The Angiosperm Phylogeny Group. An update of the Angiosperm Phylogeny Group classification for the orders and families of flowering plants: APG II. Botanical Journal of the Linnean Society, v.141, p.399-436, 2003.

BARROS, M.E. et al. Effect of extract of Phyllanthus niruri on crystal deposition in experimental urolithiasis. Urologia Research, v.34, n.6, p.351-357, 2006.

BRASIL. Farmacopéia Brasileira. 5.ed. Brasília: Agência Nacional de Vigilância Sanitária, 2010. 904p.

CHAMBERLAIN, C.J. Methods in plant histology. 5.ed. Chicago: The University of Chicago Press, 1932. 416p.

CROTEAU, R.; KUTCHAN, T. M.; LEWIS, N. G. Natural Products (Secondary Metabolites). In: BUCHANAN, B.; GRUISSEM, W.; JONES, R. (Eds.). Biochemistry \& Molecular Biology of Plants, Rockville: American Society of Plant Physiologist, 2000. p. 1250-1318.

DEVI, N. S. et al . Diversity of stomata and trichomes in Euphorbia L. - I. Bangladesh Journal of Plant Taxonomy, v.20, n.1, p.27-38, 2013.

ELUMALAI, R. et al. Foliar anatomical studies of some taxa of Euphorbiaceae. African Journal of Plant Science, v.8, n.6, p.271-277, 2014.

ESAU, K. Anatomia das plantas com sementes. 1.ed. São Paulo: Edgard Blücher, 1976. 293p.

FAHN, A. Secretory tissues in plants. 1.ed. London: Academic Press, 1979. 302p.

FIGUEIREDO, A.C.S.; BARROSO, J.M.G.; PEDRO, L.M.G.; ASCENSÃO, L. Histoquímica e citoquímica em plantas: princípios e protocolos. 1.ed. Lisboa: Faculdade de Ciências da Universidade de Lisboa, Centro de Biotecnologia Vegetal, 2007. 80p.

FUMAGALI, E. et al. Produção de metabólitos secundários 
em cultura de células e tecidos de plantas: O exemplo dos gêneros Tabernaemontana e Aspidosperma. Revista Brasileira de Farmacognosia, v.18, n.4, p.627-641, 2008.

GARCIA, C.M. et al. Estudo morfo-anatômico de Phyllanthus niruri L. e Phyllanthus tenellus Roxb. Acta Farmacêutica Bonaerense, v.23, n.1, p.67-70, 2004.

HAGEL, J.M. et al. Got milk? The secret life of laticifers. Trends in Plant Science, v.13, n.12, p.631-639, 2008.

HIROTA, B. C. K. et al. Fitoquímica e atividades biológicas do gênero Jatropha: mini-revisão. Visão Acadêmica, v.11, n.2, p.103-112. 2010.

JOHANSEN, D.A. Plant microtechnique. 1.ed. New York: McGraw-Hill Company, 1940. 523p.

JUDD, W.S.; CAMPBELL, C.S.; KELLOGG, E.A.; STEVENS, P.F. Sistemática vegetal: um enfoque filogenético. 3.ed. Porto Alegre: Artmed, 2009. 632p.

KRAUS, J.E.; ARDUIN, M. Manual básico de métodos em morfologia vegetal. 1.ed. Seropédica, Rio de Janeiro: EDUR, 1997. 198p.

LAMEIRA, O.A.; PINTO, J.E.B.P. Plantas medicinais: do cultivo, manipulação e uso à recomendação popular. 1.ed. Belém: Embrapa Amazônia Oriental, 2008. 264p.

LORENZI, H. Plantas daninhas do Brasil: terrestres, aquáticas, parasitas e tóxicas. 3.ed. Nova Odessa: Instituto Plantarum, 2000. 608p.

LORENZI, H.; MATOS, F.J.A. Plantas medicinais do Brasil: nativas e exóticas. 2.ed. Nova Odessa: Instituto Plantarum, 2008. 544p.

LUQUE, R. et al. Métodos de coloração de Roeser (1972) modificado e Kropp (1972) visando a substituição do azul de astra pelo azul de alcião 8GS ou 8GX. Acta Botanica Brasílica, v.10, n.2, p.199-212, 1996.

METCALFE, C.R.; CHALK, L. Anatomy of the Dicotyledons: Wood structure and conclusion of the general introduction, 2.ed. New York: Oxford University Press, 1985. 330p.

MILLER, L. Microtecnica e fotomicrografia. Piracicaba, Escola Superior de Agricultura "Luiz de Queiroz", 1968. $\mathrm{np}$ (Apostila de Curso).

MWINE, J. T.; VAN DAMME, P. Why do Euphorbiaceae tick as medicinal plants? A review of Euphorbiaceae family and its medicinal features. Jornal of Medicinal Plantas Research, v.5, n.5, p.652-662, 2011.

OLIVEIRA, F.; AKISUE, G.; AKISUE, M.K. Farmacognosia. 1ed. Ribeirão Preto: Atheneu, 2005. 412p.

OLIVEIRA, F.; AKISUE, G. Fundamentos de farmacobotânica e de morfologia vegetal. 3.ed. São Paulo: Atheneu, 2009. 228p.

OLIVEIRA, F.; AKISUE, G. Fundamentos de farmacobotânica. 1.ed. Rio de Janeiro, São Paulo: Atheneu, 1989. 216p.

OMS - World Health. Organization. Monographs on selected medicinal plants, 1.ed. Geneva: Organização Mundial de Saúde, 1999. 295p.

PEARSE, A.G.E. Histochemistry: theoretical and applied. 3.ed. Baltimore: Williams \& Wilkins, 1972. 758p.

SALIBA, E.O.S. et al. Ligninas - métodos de obtenção e caracterização química. Ciência Rural, v.31, n.5, p.917-928, 2001

SANTIAGO, L.J. et al. Compartmentation of phenolic compounds and phenylalanine ammonia-lyase in leaves of Phyllanthus tenellus Roxb. And their induction by copper sulfate. Annals of Botany, n.86, p.1023-1032, 2000.

SCARDELATO, J.A. et al. Ocorrência de cristais em plantas medicinais utilizadas no tratamento da nefrolitíase: paradoxo?. Revista de Ciências Farmacêuticas Básica e Aplicada, v.34, n.2, p.161168, 2013.

SECCO, R., CORDEIRO, I., MARTINS, E. R.; ZAPPI, D. 2015. Phyllanthaceae in Lista de Espécies da Flora do Brasil. Jardim Botânico do Rio de Janeiro. Disponível em: <http://floradobrasil.jbrj.gov.br/jabot/ floradobrasil/FB38571.> Acesso em: 09 Jun. 2015.

SHOBE, W.R.; LERSTEN, N.R.A technique for clearing and staining gymnosperm leaves. Botanical Gazette, v.127, n.2, p.150-152, 1967.

SILVA, A. C. C. et al. Flowering plants of the Grota do Angico Natural Monument, Caatinga of Sergipe, Brazil. Check List, v.9, n.4, p.733-739, 2013.

SILVA, M. J.; SALES, M. F. O gênero Phyllanthus L. (Phyllantheae - Euphorbiaceae Juss.) no bioma Caatinga do estado de Pernambuco - Brasil. Rodriguésia, v.55, n.84, p.101-126. 2004.

SILVA, O. L. M. Estudo taxonômico de Euphorbia L. (Euphorbiaceae) no Estado de São Paulo, Brasil. 2014. 162p. Dissertação (Mestrado em Biodiversidade Vegetal e Meio Ambiente) - Instituto de Botânica da Secretaria de estado do Meio ambiente, São Paulo.

SIQUEIRA-JACCOUD, R.J. Contribuição para o estudo da Euphorbia brasiliensis Lam. Instituto Oswaldo Cruz, v.54, n.1, p.103-113, 1956.

SOUZA, L. A. Morfologia e anatomia vegetal: células, tecidos, órgãos e plântula. 1.ed. Ponta Grossa: UEPG, 2009. 259p.

SOUZA, L. A., DARIVA, H. S., SANTOS, L. S.; CAPPAROS, E. M. Seedling structure of Euphorbia L. and Chamaesyce Gray species. Acta Scientiarum, v.36, n.1, p.95-99. 2014.

SOUZA, V.C.; LORENZI, H. Botânica sistemática: guia ilustrado para identificação das famílias de Angiospermas da flora brasileira, baseado em APG II. 1.ed. Nova Odessa: Instituto Plantarum, 2005. 640p.

STEINMANN, V., CARUZO, M.B.R., SILVA O.L.M.; RIINA, R. 2015. Euphorbia in Lista de Espécies da Flora do Brasil. Jardim Botânico do Rio de Janeiro. Disponível em: <http://floradobrasil.jbrj.gov.br/jabot/floradobrasil/ FB17561> Acesso em: 06 Jun. 2015.

THAKUR, H.A.; PATIL, D.A. Foliar epidermal studies os plants in Euphorbiaceae. Taiwania, v.59, n.1, p.59-70, 2014.

TORRES, D.S.C. et al. O gênero Phyllanthus L. (Euphorbiaceae) na Chapada Diamantina, Bahia, Brasil. Acta Botanica Brasílica, v.17, n.2, p.265-278, 2003.

VENTRELLA, M.C., ALMEIDA, A.L., NERY, L.A.; COELHO, V.P.M. Métodos histoquímicos aplicados às sementes. 1ed. Viçosa: UFV, 2013. 40p.

VERDAM, M.C.S.; DA SILVA, C.B. O estudo de plantas medicinais e a correta identificação botânica. Visão acadêmica, v.11, n.1, p.7-13, 2010. 